\title{
Radiographic study of the root canal system of mandibular incisors in Palestinian population
}

\author{
Raed Mukhaimer, Maher Jarbawi \\ Department of Conservative Dentistry, Arab American University, Jenin, Palestine \\ Email: raedmukhaimer@yahoo.com
}

Received 9 October 2013; revised 10 November 2013; accepted 20 November 2013

Copyright (c) 2013 Raed Mukhaimer, Maher Jarbawi. This is an open access article distributed under the Creative Commons Attribution License, which permits unrestricted use, distribution, and reproduction in any medium, provided the original work is properly cited.

\begin{abstract}
Aim: The aim of this study was to survey the root canal morphology of mandibular incisor teeth in a Palestinian population using radiographic approach. Materials and Methods: Five hundred and twenty two extracted mandibular incisor teeth were randomly collected from Palestinian population. The teeth were radiographed from a mesiodistal direction and examined for the presence of a second canal and for the type of canal configuration. Results: All teeth had single root. Three hundred and sixty nine teeth $(\mathbf{7 0 . 7 \% )}$ had one canal (type I Vertucci classification). The rest (29.3\%) had a second canal (type II and III). Conclusion: Mandibular central and lateral teeth were mostly found to have one root and Type I canal system.
\end{abstract}

Keywords: Mandibular Incisors; Radiography; Root Canal System

\section{INTRODUCTION}

Successful outcomes of endodontic treatment depend on the identification of all root canals which in turn guarantee complete extirpation of pulp tissue, proper chemomechanical cleaning and shaping and three dimensional obturation of the root canal system with an inert filling material. Undetected extra roots or root canals had been considered as a major reason for failure of root canal treatment [1].

Many of the challenges faced during root canal treatment may be directly attributed to an inadequate understanding of the canal morphology of teeth. Studies had shown that anatomical variations can occur in all groups of teeth with different incidences with respect to number of roots and root canals and with respect to root/canal system configuration [2-4].

Different techniques had been used to study the root canal anatomy of the mandibular incisors. Vertucci [2] used the clearing technique to study the root canal morphology of 300 extracted mandibular incisors and found that two canals were present in $30 \%$ of mandibular central incisors and in $25 \%$ of mandibular lateral incisors. Using the same technique, Miyashita et al. reported that more than $85 \%$ of root canals possessed a single canal [5]. Mauger et al. [6] used root sectioning to assess the canal anatomy at different root levels in 100 lower incisors and reported that $98 \%-100 \%$ of the teeth had one canal in the area situated 1 - $3 \mathrm{~mm}$ above the apex.

In a study conducted in Iranian population using Cone-Beam Computed Tomography, 632 central incisors and 614 lateral incisors were examined. A second canal was found in $27.3 \%$ of central incisors and $29.4 \%$ of lateral incisors [7]. De Oliveira et al. [8] used digital radiography to analyze the presence of an extra canal in lower incisors. The in vitro study was conducted on 200 mandibular incisors positioned on a model, simulating the mandibular dental arch. Digital radiographs were taken from the mandibular incisors in both buccolingual and mesiodistal directions. The digital radiography showed presence of bifurcation in $20 \%$ of teeth evaluated in the mesiodistal direction. In the buccolingual direction, $15 \%$ presented bifurcation or characteristics indicating bifurcation.

It had been reported that root canal systems of mandibular incisors may vary according to race. In his study, in Southern Chinese population, Walker had found that $28 \%$ of mandibular incisors possess two separate canals [9]. Boruah and Bhuyan [10] reported an incidence of $36.25 \%$ of the roots possessed two canals in a population of North East India. Sert et al. investigated the root canal configurations of mandibular permanent teeth in Turkish population and reported the presence of a second canal in $68 \%$ of mandibular central incisors and $63 \%$ of lateral incisors [11].

No data are available on the root canal morphology of 
mandibular incisors in Palestine. The aim of the present investigation was to find out the incidence of second root canal and the type of root canal configuration of mandibular incisors amongst Palestinian population.

\section{MATERIALS AND METHODS}

Five hundred and twenty two extracted mandibular incisors were randomly collected from several private dental clinics. The Ministry of Health Ethics Committee approved the study. All individuals agreed to participate by signing an informed consent form. No attempt was made to differentiate between central and lateral incisors. All teeth included in the study had intact clinical crowns and fully-formed roots. The teeth were cleaned from any remaining calculus and soft tissue by scaling and washed with tap water and then placed in $10 \%$ formalin solution.

Teeth were arranged in a group of three over one X-ray film (Ektaspeed Plus, Eastman Kodak, Rochester, NY,USA) and radiographed in a mesiodistal direction using paralleling technique. Time was set to 0.1 second. To minimize variations, target film distance was kept to 5 $\mathrm{cm}$. The X-rays were developed according to the manufacturer instructions.

The resultant images were examined by the author for the presence of a single root canal or bifurcated root canal. All radiographs were examined systematically in a darkened room using an illuminated viewer box with magnification $(2.5 \times)$.The configuration of each canal was also categorized into the first four types of Vertucci's classification 2 as follows:

Type I: single canal is present from the pulp chamber to the apex

Type II: two separate canals leave the pulp chamber but join short of the apex to form one canal

Type III: one canal leaves the pulp chamber but divides into two within the body of the root canals then merge again to exit as one canal

Type IV: two separate canals are present from the pulp chamber to the apex

The four canal configurations are shown in Figure 1.

\section{RESULTS}

All examined central and lateral incisors had only a single root. The results are summarized in Table 1 that shows the number and percentages of each canal type in mandibular incisors. Of the 522 teeth studied, the majority $(70.7 \%)$ displayed a type I root canal configuration, type II was found in $16.3 \%$ cases and type III in $13 \%$. An overall of one hundred and fifty three teeth (29.3\%) possessed a second canal. Figures 2, $\mathbf{3}$ and $\mathbf{4}$ show samples of the radiographs representing Vertucci's canal configuration type I, II, and III respectively.

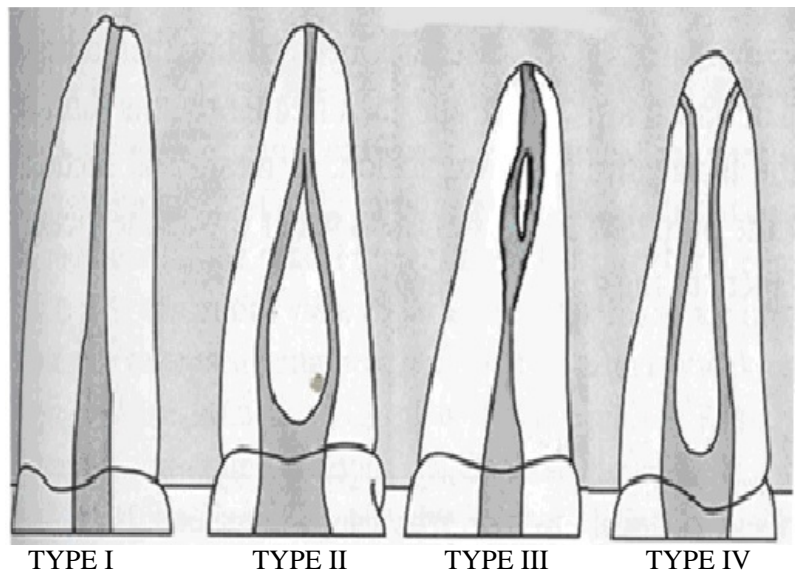

Figure 1. Vertucci root canal classification.

Table 1. number and percentages of mandibular incisor teeth with various types canal configuration based on Vertucci's classification.

\begin{tabular}{cc}
\hline Canal configuration & number of teeth (\%) \\
\hline Type I $(1-1)$ & $369(70.7 \%)$ \\
Type II $(2-1)$ & $85(16.3 \%)$ \\
Type III $(1-2-1)$ & $68(13.0 \%)$ \\
Type IV $(2-2)$ & $0(0 \%)$ \\
Total & $522(100 \%)$ \\
\hline
\end{tabular}

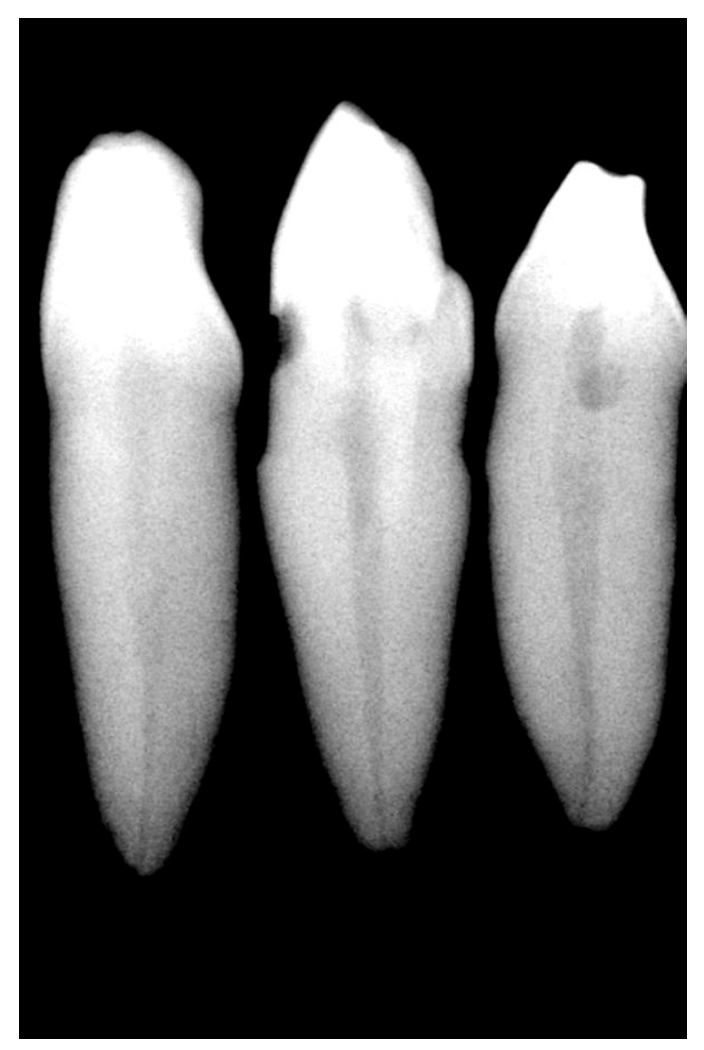

Figure 2. Selected radiograph of single canal (type I) of mandibular incisors. 


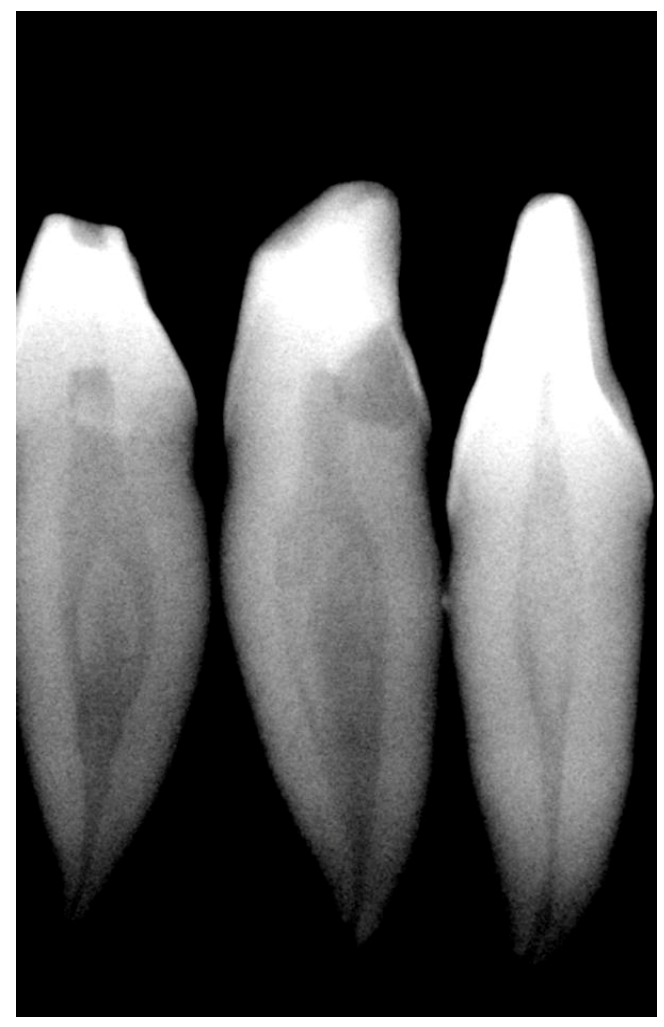

Figure 3. Selected radiograph of two canals (type II) of mandibular incisors.

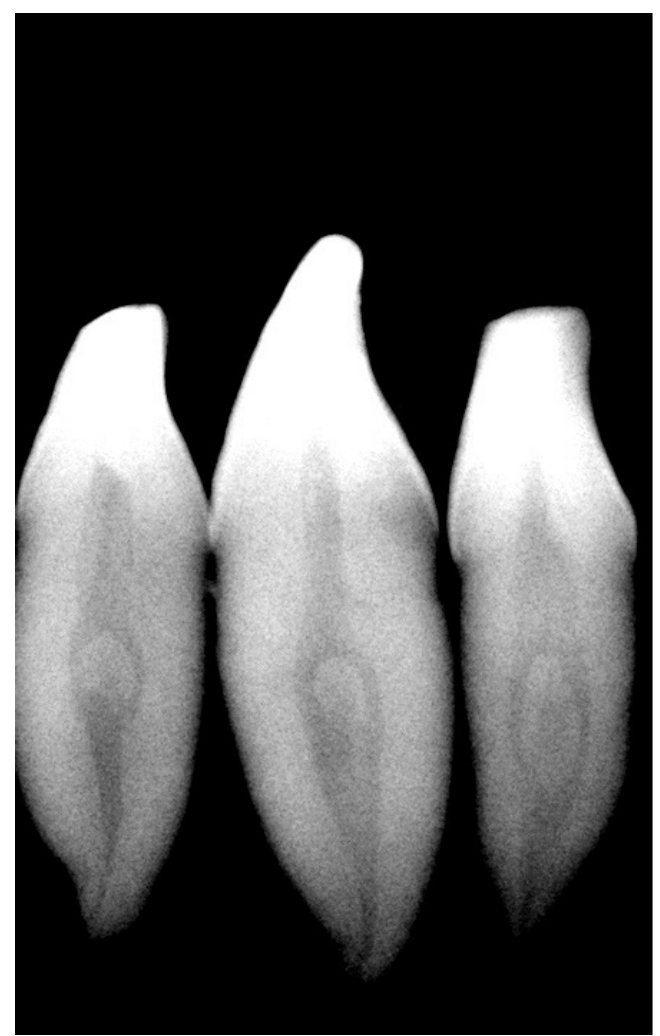

Figure 4. Selected radiograph of two canals (type III) of mandibular incisors.

\section{DISCUSSION}

A variety of techniques have been used to study the internal anatomy of lower incisors $[5,6,8]$. Although radiography is unlikely to show the complexities of the root canal system such as lateral canals and eccentrically located apical foramina [12], it may demonstrate the main anatomical features. Hence the present study aimed to investigate the incidence of bifurcated canals and the type of canal configuration, this technique was used in this study and the examined teeth were radiographed in a mesiodistal direction. Radiographs may be the only noninvasive means clinically to provide clues about the morphology of the root canal system. This technique proved to be simple and fast and needs little equipment.

Successful root canal therapy depends on sound knowledge of the normal and abnormal internal anatomy of the treated tooth. Investigators have shown multiple foramina, loops, fins, deltas, additional canals, accessory canals, intercanal connections and "C-shaped" canals. Consequently the practitioner must treat each tooth assuming that complex anatomy occurs often enough to be considered normal.

Mandibular incisors have been traditionally treated as teeth with a single canal. Anatomical studies had shown that a considerable percentage of mandibular incisors ranging between $12.4 \%$ [5] and 68\% [11] posses a dentinal bridge in the pulp chamber that divides the root into two canals. The two canals usually join and exit through a single apical foramen, but they may persist as two separate canals.

Vertucci [2] examined the root canal morphology of 300 mandibular anterior teeth and reported a second canal in $27.5 \%$ of mandibular incisors. Al-Qudah and Awawdeh [13] examined the root canal morphology of 450 mandibular anteriors in Jordanian population and reported a second canal in $26.2 \%$ of mandibular incisors. A higher incidence (36.25\%) was reported by Boruah and Bhuyan [14] who investigated the root canal anatomy of mandibular incisors of North East Indian population. In a recent study conducted by Al-Fouzan et al, 30\% of mandibular incisors of Saudi population were found to have a second canal [15]. The differences between these morphology studies may be related to variations of examination techniques, sample size, classification systems and ethnic background of tooth sources.

In the present study, $29.3 \%$ of the mandibular incisors possessed a second root canal. All of these canals joined and exited in a single foramen (Type II and III). The frequency of two canals in the present study was within the range of previous reports and very close to the frequentcies reported in the Middle East region (26.2\% in Jordanian population, $30 \%$ in Saudi population and $28.3 \%$ in Iranian population). 
The results of this investigation indicate that about one third of lower incisors in Palestinian population has a second canal. The clinicians should always take this anatomical variation into consideration when treating this group of teeth as this relatively high proportion is not routinely found during clinical procedure. Clinicians usually fail to recognize the presence of a second canal either due to lake of knowledge of root canal morphology or due to lake of experience and skills to negotiate that canal [16] with a subsequent failure of root canal treatment.

To overcome the challenge of locating the second canal and optimize the access preparation, the traditional lingual access of lower anteriors had been modified by extending the access toward the cingulum [17]. With the invention of highly aesthetic restorative materials, some authors had suggested labial or incisal approach for mandibular incisors as an alternative approach of lingual access $[18,19]$.

For several reasons, the clinician should not feel secure when treating only one canal. An important point is that, the two canals in lower incisors, if present, usually join 1-3 mm from the apex. If one canal is prepared and filled shorter from this joining point, the second canal will become necrotic and open directly into the periapical area through the apical foramen [20]. Another point is that, when only one canal is treated, pulp tissue in the second canal can ultimately release harmful substances through a secondary canal to the interior space of the periodontium ligament [21]. In both situations, a subsequent failure of root canal treatment may occur.

\section{CONCLUSION}

Based on the findings of this study, a high incidence of two canals in the lower incisor teeth had been found in Palestinian population. The clinician must be alert for the possibility of a bifurcated root canal in these teeth as this may complicate root canal treatment.

\section{REFERENCES}

[1] Slowey, R.R. (1974) Radiographic aids in the detection of extra root canals. Oral Surgery Oral Medicine Oral Pathology, 37, 762-772. http://dx.doi.org/10.1016/0030-4220(74)90142-X

[2] Vertucci, F.J. (1974) Root canal anatomy of the mandibular anterior teeth. Journal of American Dental Association, 89, 369-371.

[3] Kulild, J.C. and Peters, D.D. (1990) Incidence and configuration of canal systems in the mesiobuccal root of maxillary first and second molars. Journal of Endodontics, 16, 311-317. http://dx.doi.org/10.1016/S0099-2399(06)81940-0

[4] Gulabivala, K., Aung, T.H., Alavi, A. and Ng, Y.L. (2001)
Root and canal morphology of Burmese mandibular molars. International Endodontic Journal, 34, 359-370. http://dx.doi.org/10.1046/j.1365-2591.2001.00399.x

[5] Miyashita, M., Kasahara, E., Yasuda, E. and Yamamoto, A. (1997) Root canal system of the mandibular incisor. Journal of Endodontics, 23, 479-484. http://dx.doi.org/10.1016/S0099-2399(97)80305-6

[6] Mauger, M.J., Schindler, W.G. and Walker, W.A. (1998) An evaluation of canal morphology at different levels of root resection in mandibular incisors. Journal of Endodontics, 24, 607-609.

http://dx.doi.org/10.1016/S0099-2399(98)80120-9

[7] Aminisobhani, M., Sadegh, M., Meraji, N., Razmi, H. and Kharazifard, M.J. (2013) Evaluation of the Root and Canal Morphology of Mandibular Permanent Anterior Teeth in an Iranian Population by Cone-Beam Computed Tomography. Journal of Dentistry of Tehran University of Medical Sciences, 10, 358-366.

[8] de Oliveira, S.H., de Moraes, L.C, Faig-Leite, H., Camargo, S.E. and Camargo, C.H. (2009) In vitro incidence of root canal bifurcation in mandibular incisors by radiovisiography. Journal of Applied Oral Sciences, 17, 234-239.

[9] Walker, R.T. (1988) The root canal anatomy of mandibular incisors in a southern Chinese population. International Endodontic Journal, 21, 218-223. http://dx.doi.org/10.1111/j.1365-2591.1988.tb00978.x

[10] Boruah, L.C. and Bhuyan, A.C. (2011) Morphologic characteristics of root canal of mandibular incisors in North-East Indian population: An in vitro study. Journal of Conservative Dentistry, 14, 346-350. http://dx.doi.org/10.4103/0972-0707.87195

[11] Sert, S., Aslanalp, V. and Tanalp, J. (2004) Investigation of the root canal configurations of mandibular permanent teeth in the Turkish population. International Endodontic Journal, 37, 494-499.

http://dx.doi.org/10.1111/j.1365-2591.2004.00837.x

[12] Altman, M., Guttuso, J., Seidberg, B.H. and Langeland, K. (1970) Apical root canal anatomy of human maxillary central incisors. Oral Surgury Oral Medicine Oral Pathology, 30, 694-699. http://dx.doi.org/10.1016/0030-4220(70)90396-8

[13] Al-Qudah, A.A. and Awawdeh L.A., (2006) Root canal morphology of mandibular incisors in a Jordanian population. International Endodontic Jounal, 39, 873-877. http://dx.doi.org/10.1111/j.1365-2591.2006.01159.x

[14] Boruah, L.C. and Bhuyan, A.C. (2011) Morphologic characteristics of root canal of mandibular incisors in North-East Indian population: An in Vitro study. Journal of Conservative Dentistry, 14, 346-350.

[15] Al-Fouzan, K.S., AlManee, A., Jan, J. and Al-Rejaie, M. (2012) Incidence of two canals in extracted mandibular incisors teeth of Saudi Arabian samples. Saudi Endodontic Journal, 2, 65-69.

http://dx.doi.org/10.4103/1658-5984.108151

[16] Ingle, J. and Bakland, L. (2002) Endodontics. 5th Edition, BC Decker, Hamilton.

[17] Janik, J.M. (1984) Access cavity preparation. Dental 
Clinics of North America, 28, 809-818.

[18] Logani, A., Singh, A., Singla, M. and Shah, N. (2009) Labial access opening in mandibular anterior teeth: An alternative approach to success. Quintessence, 40, 597602.

[19] Clements, R.E. and Gilboe, D.B. (1991) Labial endodontic access opening for mandibular incisors: Endodontic and restorative considerations. Journal of Canadian Den- tal Association, 57, 587-589.

[20] Kartal, N. and Yanikoglu, F. (1992) Root canal morphology of mandibular incisors. Journal of Endodoncs, 18, 562-564.

[21] Benjamin, K.A. and Dowson, J. (1974) Incidence of two root canals in human mandibular incisor teeth. Oral Surgery Oral Medicine Oral Pathology, 32, 122-126. http://dx.doi.org/10.1016/0030-4220(74)90323-5 